\title{
THE THERAPEUTIC EFFECT OF CAMPTOTHECIN IN INDUCED ORAL SQUAMOUS CELL CARCINOMA (EXPERIMENTAL STUDY)
}

\author{
Hend M. Helmy ${ }^{1} M S C$, Zeinab E. Darwish ${ }^{2} P h D$, Sahar M. El-Sheikh ${ }^{3} P h D$, Marwa M. \\ Afifi $^{4} P h D$
}

\begin{abstract}
INTRODUCTION: Head and neck squamous cell carcinoma (HNSCC) is the sixth most common cancer worldwide, affecting over 400,000 patients, and leading to over 200,000 deaths annually. Camptothecin (CPT), is a potent widely used chemotherapeutic drug. It shows a significant antitumor activity against various types of cancer. It inhibits the activity of DNA topoisomerase I enzyme (TOP I) during the S phase of the cell cycle leading to persisting single-stranded DNA breaks.

OBJECTIVES: To study the therapeutic efficacy of CPT chemotherapeutic drug against induced oral squamous cell carcinoma (OSCC). Also the study will evaluate the treatment, by the use of proliferative immune-histochemical marker (PCNA).

MATERIALS AND METHODS: Squamous cell carcinoma will be chemically induced in thirty Syrian hamsters. Then they will be divided into two groups, 15 per each. One group will be treated with CPT, The other group will be treated with saline as negative control group. RESULTS: CPT treated animals showed significant results over the control group.

CONCLUSIONS: CPT induced apoptosis in tumor cells and enhanced survival rates in comparison to control group.

KEYWORDS: Oral squamous cell carcinoma, hamsters, Camptothecin.
\end{abstract}

1. Master in Oral Pathology Department, Faculty of Dentistry, Alexandria University.

2. Professor in Oral Pathology Department, Faculty of Dentistry, Alexandria University.

3. Professor in Oral Pathology Department, Faculty of Dentistry, Alexandria University.

4. Lecturer in Oral Pathology Department, Faculty of Dentistry, Alexandria University.

Corresponding author

E-mail: hendsadec@gmail.com

\section{INTRODUCTION}

Oral squamous cell carcinoma (OSCC) is the sixth most common cancer worldwide that invades local tissue, metastasizes and has high mortality rate with overall 5 years survival rate $(1,2)$. Conventional treatment strategies for early diagnosed OSCC are surgery and radiotherapy, either as single modality or in a combination therapy, with no or minimal functional and physical morbidity. However, because of the complex anatomy and the vital functions of the facial structures, the extent of surgery will always be limited $(3,4)$. Chemotherapeutic drugs commonly used targeting OSCC includes 5-fluorouacil, cisplatin and paclitaxel (5). Unfortunately, the majority of them remain palliative, not curative (6).

A widely used chemotherapeutic drug is Camptothecin (CPT). Wall and Wani were the first researchers to isolate CPT from the barks of a plant called Camptotheca acuminate in 1966. Camptothecin is a cytotoxic, quinoline alkaloid characterized by the planar pentacyclic ring system (7). It binds to the DNA topoisomerase I (TOP I) which is an essential enzyme that relaxes supercoiled DNA prior to transcription through the formation of single strand breaks and religation. This union forms a very stable structure called the covalent complex. Upon binding to TOP I, CPT selectively induce cytotoxicity to the cells' replicating DNA during the $\mathrm{S}$ phase. Its toxicity is primarily a result of conversion of single-strand breaks into double-strand breaks by preventing religation when the replication fork collides with the covalent complex. Camptothecin interacts only with those cells which are in the S-phase. This means that CPT is toxic to the cells that are undergoing DNA synthesis. Cancerous cells are rapidly replicating and they spend more time in the S-phase in relation to healthy tissues, and therefore they are killed with much higher efficiency than the healthy host tissues. Such selectivity of cytotoxicity is a promising property of CPT (8-10). Several studies have shown that CPT and its derivatives can strongly induce apoptosis in human leukemic cells, prostate (11), colon (12), and breast cancer (13).

The aim of the present work was to study the therapeutic efficacy of CPT on chemically induced OSCC in hamsters' buccal pouches. Moreover the study will evaluate the treatment, by the use of proliferative immunohistochemical marker (PCNA).

\section{MATERIALS AND METHODS}

The study was performed in the Faculty of Dentistry, Alexandria University after gaining the approval of the Research Ethics Committee. Thirty Syrian golden male hamsters (Five weeks old), weighting 80-110 gram were obtained from holding company for biological products and vaccines (VACSERA), Helwan, Cairo, Egypt. They were housed in show box cages (Technoplast, Italy) one per cage, at the experimental animal unit in the Medical Technology Center (Medical Research Institute, Alexandria University, Egypt).

\section{a- Cancer Induction}

The animals' left buccal pouches were painted with $0.5 \% 7$, 12-dimethyl 1, 2-benzanthracane (DMBA) (Sigma-Aldrich) dissolved in liquid paraffin using a number 4 paint brush. Following a standard carcinogenesis protocol, this procedure was repeated 3 times per week for 18 weeks or upon developing oral neoplasms. 


\section{b- Treatment Plan}

After cancer induction, the hamsters were injected with the desired treatment according to the planned protocol using an insulin syringe. During the treatment procedure they were lightly sedated using ketamine hydrochloride. The control group received saline of $0.9 \%$ concentration. The CPT group was injected with a dose of $2 \mathrm{mg} / \mathrm{kg}$ (9). The hamsters in the control group received saline, with the same dose. Each group received the proposed treatment three times per week for one week.

After treatment, biopsies were extracted from the sacrificed animals in both groups. They were fixed in 10\% buffered formaldehyde solution and embedded in paraffin. Sections $4 \mu \mathrm{m}$ thick, stained with hematoxylin and eosin (H\&E stain) to confirm and grade the type of the induced carcinoma and to count the apoptotic bodies after treatment. Other $4 \mu \mathrm{m}$ thick sections were mounted on super frost pluscoated glass slides for immunohistochemical evaluation of the proliferation activity using monoclonal proliferation cell nuclear antigen (PCNA). The immunostaining results were scored using an image analyzer (Image J software).

\section{d- Evaluation of the Proposed Treatment}

\section{i- Evaluation of Tumor Volume}

Tumor volume was measured in all animals just prior to treatment using a caliber. The same measurements were performed weekly after treatment over a period of 4 weeks. Tumor volume percent change were calculated as follows: [(volume by the end of the 4th week - volume before treatment) /volume before treatment] x100.

\section{ii- Survival Time and Increased Life Span}

Animal survival time in terms of days and increased life span were recorded as well (mean, standard deviation) and compared to the values for the control group.

\section{e- Statistical analysis}

The data were collected, tabulated and statistically analyzed using the SPSS system (release 11.0 software). All results were expressed as (mean $\pm \mathrm{SD}$ ). Tumor volume changes before and after treatment was analyzed statistically using paired t-test.

The influences of the numerical variables on the survival rate were examined by univariate analysis and multivariate regression analysis (Cox proportional hazards model). Paired t-test was used to analyze the apoptotic index between study groups. Also it was used to analyze the mean area percent and mean optical density of the immunohistochmical results. In all statistical results, a p value $<0.05$ was considered significant.

\section{RESULTS}

\section{a. Sequential Clinical Changes during Period of Carcinogenesis}

The hamsters in the study groups were observed for the clinical changes during the period of carcinogenesis. After few weeks non-scrapable white lesions (leukoplakia) in different forms with sloughing of the mucosa started to be seen. Afterwards, some lesions turned into mixed white and red lesions (erythroleukoplakia). Meanwhile by the end of the carcinogenesis process, well developed oral tumors were observed, as exophytic masses with smooth or lobulated surfaces. (Figure 1)

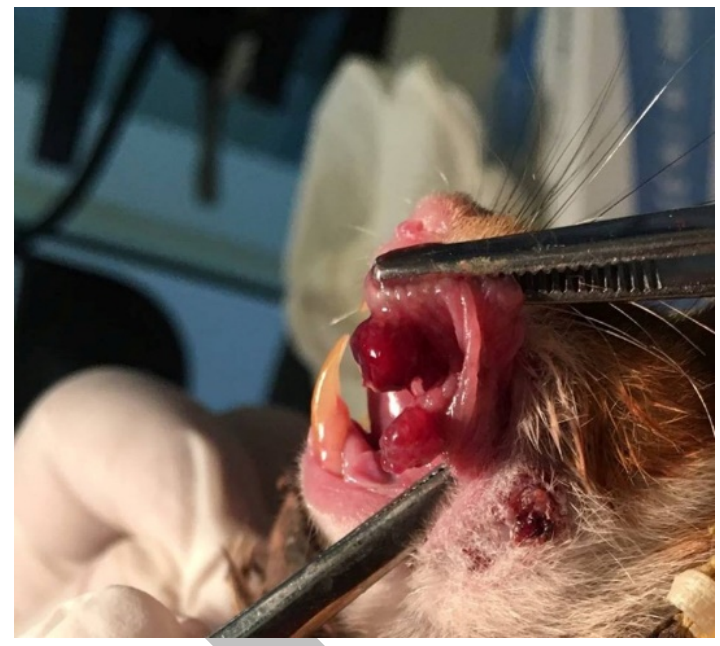

Figure 1: Multiple Exophytic Masses wither Smooth or Nodular Surface in HBP.

\section{b- Sequential Histological Changes during Period of} Carcinogenesis

Hamsters were sacrificed periodically during the carcinogenesis period to evaluate and grade the histological changes of the tumor. After few weeks of cancer induction, the epithelial dysplastic changes started to appear, where the hamster buccal pouch (HBP) showed mild epithelial dysplasia, then moderately then the dysplastic changes turned into severe epithelial dysplasia, and carcinoma in situ. (Figure 2). At the end of cancer induction, some tissues revealed early invasive OSCC with evident points of invasion of the malignant epithelial cells into the underlying lamina propria. By the end of carcinogenesis, different grades of differentiation, well, moderately and poorly differentiated OSCC was observed (Figure 3).

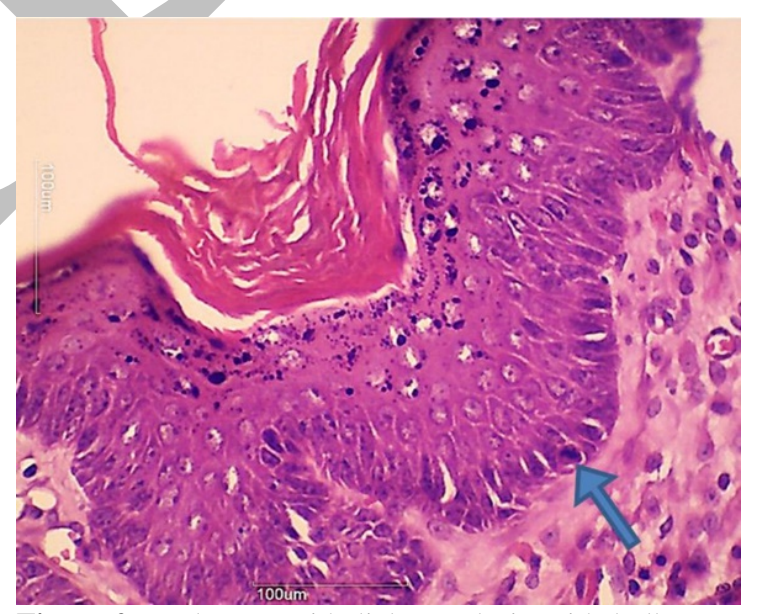

Figure 2: Moderate Epithelial Dysplasia with bulbous rete pegs with abnormal mitotic figures (Arrow) (H\&E X 400). 


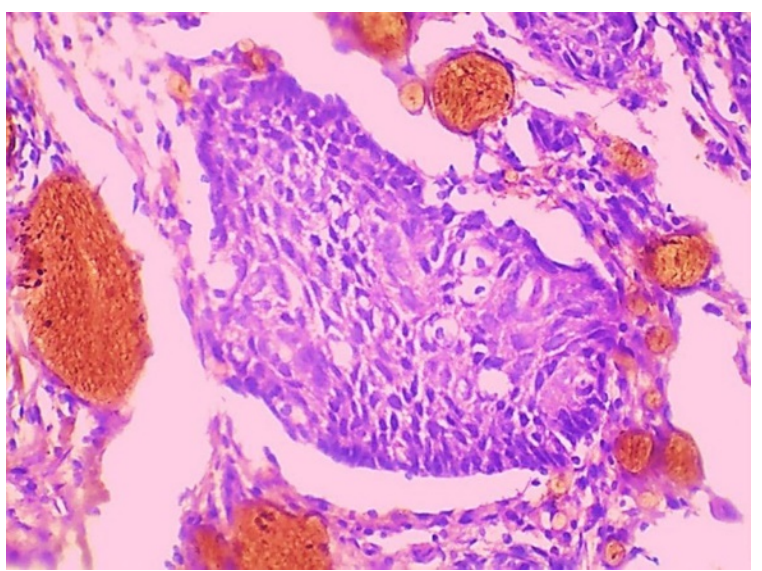

Figure 3: Moderately Differentiated SCC Showing a Cell Nest (H\&E X 400).

\section{c- Grouping and Treatment Plan}

At the end of carcinogenesis process, three hamsters died during the induction process and the remaining hamsters developed tumor masses with incident rate of $100 \%$ and tumor multiplicity of $2.4 \pm 1.53$ tumors per hamsters. They were divided blindly into 2 groups, according to the type of the proposed treatment.

\section{d- Evaluation of the Proposed Treatment}

\section{i- Evaluation of Tumor Volume}

The tumor volumes in the study group were recorded weekly till the 4th week after treatment. They were measured before and after treatment and the results was as follows: In the control saline group, some tumors continued to increase in their volume by a percent change of $6.8 \%$. In the CPT group, the treated tumors recorded significant decrease in the mean tumor volume by $-28.5 \%(\mathrm{p}<0.05)$ as shown in Table 1.

Table 1: Tumor volume* in $\mathrm{mm}^{3}$ (mean \pm SD) before and after treatment, percentage of volume change (mean $\pm \mathrm{SD}$ ).

\begin{tabular}{||c|c|c|c|c|c||}
\hline $\begin{array}{c}\text { Group } \\
(\mathbf{n}=\mathbf{1 2} \\
\mathbf{0})\end{array}$ & $\begin{array}{c}\text { Treatme } \\
\mathbf{n t}\end{array}$ & $\begin{array}{c}\text { Mean } \\
\text { tumor } \\
\text { volume } \\
\text { before } \\
\text { treatment* }\end{array}$ & $\begin{array}{c}\text { Mean } \\
\text { tumor } \\
\text { volume } \\
\text { after } \\
\text { treatment } \\
*\end{array}$ & $\begin{array}{c}\text { Percent } \\
\text { age of } \\
\text { volume } \\
\text { change }\end{array}$ & $\begin{array}{c}\boldsymbol{P} \\
\text { valu } \\
\mathbf{e}\end{array}$ \\
\hline $\begin{array}{c}\text { Group } \\
\text { I } \\
(\mathrm{n}=15)\end{array}$ & Saline & $\begin{array}{c}141.0 \\
( \pm 90.1)\end{array}$ & $\begin{array}{c}148.2 \\
( \pm 91.2)\end{array}$ & $\begin{array}{c}6.8 \\
( \pm 2.4)\end{array}$ & $\begin{array}{c}0.00 \\
8^{* *}\end{array}$ \\
\hline $\begin{array}{c}\text { Group } \\
\text { II } \\
(\mathrm{n}=15)\end{array}$ & CPT & $1196( \pm 451)$ & $854( \pm 169)$ & $\begin{array}{c}-28.5 \\
( \pm 1.6)\end{array}$ & 0.01 \\
$0 * *$ \\
\hline
\end{tabular}

* Tumor volume in $\mathrm{mm}^{3}=\mathrm{D} \max \mathrm{X}(\mathrm{D} \min )^{2} / 2$.

** Statistically significant $(p<0.05)$ in comparison between mean tumor volume before and after treatment in each group.

\section{ii- Survival Rate}

The control saline group, showed mean survival rate of 12 $( \pm 1.4)$. The CPT group, revealed significant increase in the mean survival rate which was $24( \pm 3.3)$. The mean survival rate $( \pm$ SD) and increased life span (ILS \%) are summarized in Table 2.
Table 2: Survival rate in days (mean \pm SD) after treatment and increased life span (ILS \%)

\begin{tabular}{|c|c|c|c|c|c||}
\hline $\begin{array}{c}\text { Group } \\
(\mathbf{n}=120)\end{array}$ & Treatment & $\begin{array}{c}\text { Mean } \\
\text { survival } \\
\text { time }\end{array}$ & & $\begin{array}{c}\text { ILS } \\
\text { \%* }\end{array}$ & P value \\
\hline $\begin{array}{c}\text { Group I } \\
(\mathrm{n}=15)\end{array}$ & Saline & $\begin{array}{c}12 \\
( \pm 1.4)\end{array}$ & & & 0.001 \\
\hline $\begin{array}{c}\text { Group } \\
\text { II } \\
(\mathrm{n}=15)\end{array}$ & CPT & $\begin{array}{c}24 \\
\pm 3.3) \\
* *\end{array}$ & & $72 \%$ & 0.001 \\
\hline
\end{tabular}

${ }^{*} I L S \%=\left(\left(\frac{\text { mean survival time of treated group }}{\text { mean survival time of control group }}\right)-1\right) \times 100$

** Statistically significant $(p<0.05)$ in comparison to the mean survival rate of the control group.

\section{e- Microscopical Evaluation}

\section{I- Apoptotic Index (AI) Analysis}

In the saline control group the quantitative AI analysis revealed mean values of $1.24( \pm 1.47)$ and in the CPT group, the mean AI was $11.3( \pm 1.54)$ and both were not statistically significant of ( $>0.05)$. Apoptotic Index after Treatment (mean \pm SD) is summarized in Table 3.

Table 3: Apoptotic Index in All Groups after Treatment (mean \pm SD).

\begin{tabular}{|c|c|c||}
\hline $\begin{array}{c}\text { Group } \\
(\mathbf{n}=\mathbf{1 2 0})\end{array}$ & Treatment & Apoptotic Index \\
\hline Group I (n=15) & Saline & $1.24( \pm 1.47)$ \\
\hline $\begin{array}{c}\text { Group II } \\
(\mathrm{n}=15)\end{array}$ & CPT & $11.3( \pm 1.54)$ \\
\hline
\end{tabular}

\section{II- Immunohistochemical Results}

The immunohistochemical proliferation assay was done among the study groups, using PCNA proliferative marker. The immunoreaction in both groups showed variations in both, mean area percent (MA \%) and mean optical density (MOD).

In the control saline group, the malignant epithelial cells showed intense nuclear immunoreactivity to PCNA. Most of the cells showed positive reaction, indicating high proliferative index in this group, it also showed the highest MA \% of $83.2 \pm 2.7$ and the highest MOD of $73.9 \pm 58.1$ (Figure 4). In the free CPT group, the immunoreactivity of malignant epithelial cells to PCNA was decreased. Intense nuclear immunoreaction was noted at the peripheral cells, lining the cell nests. The MA\% decreased in comparison to the control saline group to $30.4 \pm 3$.2. The MOD also, decreased to $44.0 \pm 5$.3. The MA was of significant value $(\mathrm{p}<0.05)$ (Figure 5 ). 


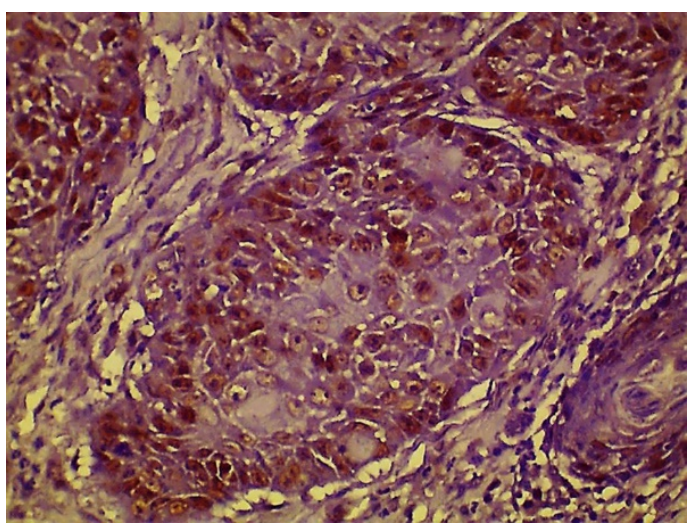

Figure 4: Intense Nuclear Immunoreaction to PCNA throughout Malignant Epithelial Cells in Control Saline Group (PCNA X 400).

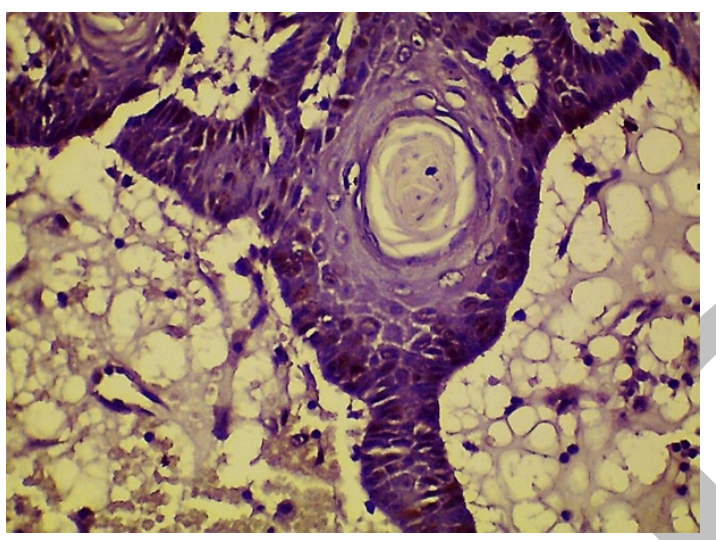

Figure 5: Positive Nuclear Immunoreaction Limited to Some Peripheral Malignant Epithelial Cells with Negative Immunoreaction Seen in the Rest, in the CPT treated Group (PCNA X400).

\section{DISCUSSION}

Head and neck cancers represent a major international health problem worldwide, $90 \%$ of them are oral squamous cell carcinoma (OSCC). The survival rate of cancer patients is heavily dependent on early diagnosis. The average 5 year survival rate following diagnosis is $42 \%$ to $64 \%$ and this prognosis has not changed in the past 60 years (14). Conventional treatment of OSCC, is surgery and radiotherapy either as a single modality or in a combination therapy. Most early-stage OSCC can be locally excised and treated with radiotherapy, with no or minimal functional and physical morbidity (3, 4). Meanwhile, conventional therapy is far less successful for patients with advanced, recurrent and metastatic cancer (15).

The DMBA-induced squamous cell carcinoma in hamster buccal pouch represents the closest relationship between cellular and molecular events that occurred in the development of pre-malignant and malignant lesions in human beings. These include types of mutations, changes of expression of oncogenes and markers of cell proliferation (16). In the present study, the intra oral tumors started to develop after application of DMBA at $0.5 \%$ concentration three times per week, for a period of 16 weeks. This goes with the results of Taraboletti G and Giavazzi R. on their work for production of cancer angiogenic model, they developed a clinically visible exophytic masses after 16 weeks of application (17). On the other hand Bampi V. et al. succeeded to develop a well differentiated tumors only after 8 weeks of application. They induced the cancer on two stages: an initiation phase, induced by a carcinogen, and a phase of tumor promotion, stimulated by a promoter to minimize the constant handling throughout the experiment with the animal and the carcinogen (18).

Many chemotherapeutic drugs are used in treating different types of cancers, among them camtothecin (CPT) which has a prominent role as anticancer treatment (10). In this research, the clinical results in terms of tumor volume revealed the effectiveness of treating the induced OSCC with CPT. The survival rate of the hamsters treated with CPT showed prolonged life span with significant decrease in the mean tumor volume. This was in accordance with Sanli et al. in their work, they use CPT as a single agent to treat both recurrent and metastatic colorectal cancer. They revealed higher results in the treatment of colorectal carcinoma with prolonged life span (19). Similar results were also obtained by Rosati and Cordio S. They examined the anti-tumor effect of CPT on advanced cases of colorectal cancer with more than $50 \%$ decrease in the tumor volume compared to pre-treatment measurements (20).

In the current study, the histological results in terms of apoptotic index (AI) confirmed that CPT had an effective cytotoxicity that could be used in the treatment of cases of OSCC. The AI recorded higher values in the group treated with CPT, with the presence of different stages of apoptosis. This suggested the success in targeting the tumor site with CPT. This was also reported by Rapic et al., they revealed a significant increase in apoptotic index after treatment with CPT over 5-fluorouacil by using an in vitro and in vivo model of colorectal cancer (21).

The use of different types of microscopical assessments to characterize various tissue changes is essential to report the proposed treatment. In the present investigation, the therapeutic efficacy of the proposed treatment was done by assessing the AI by light microscope, whereas, the immuno-histochemical analysis was done to assess the proliferative activity by the PCNA marker. The histological results confirmed the therapeutic anti-cancer effect of CPT in the treatment of induced OSCC in HBP. The positive nuclear immunoreactivity showed its highest significant values in the control group treated with saline over the CPT treated group. On the contrary decreased or diminished PCNA immunoexpression was strongly noted in the group treated with CPT. Tumor regression is noted with an inverse correlation between PCNA as a proliferative marker and tumor apoptotic index. These results are in accordance with Qiao et al., who used PCNA as a proliferative marker to test the effect of different chemotherapeutic drugs including CPT in prostate carcinoma cell line (22).

\section{CONCLUSION}

Camptothecin can effectively decrease the mean tumor volume, increased survival rate and enhanced mean AI. Also it lowered the degree of cellular proliferation inside the tumor tissue.

\section{CONFLICT OF INTEREST}

The authors declare that they have no conflicts of interest.

\section{REFERENCES}

1. Ayllon Barbellido S, Campo Trapero J, Cano Sanchez J, Perea Garcia MA, Escudero Castano N, Bascones Martinez A. Gene therapy in the management of oral cancer: review of the literature. Med Oral Patol Oral Cir Bucal. 2008;13:E15-21. 
2. Van Monsjou HS, Balm AJ, Van den Brekel MM, Wreesmann VB. Oropharyngeal squamous cell carcinoma: a unique disease on the rise? Oral Oncol. 2010;46:780-5.

3. Vijayakumar M, Burrah R, Sabitha KS, Nadimul H, Rajani $\mathrm{BC}$. To operate or not to operate in the neck in early cancer of the tongue? A prospective study. Indian J Surg Oncol. 2011;2:172-5.

4. Popat K, McQueen K, Feeley TW. The global burden of cancer. Best Pract Res Clin Anaesthesiol. 2013;(4):399408.

5. Feng L, Eil LL, Soloveiv MM, Wang DS, Zhang BO, Dong YW. Synergistic cytotoxicity of cisplatin and Taxol in overcoming Taxol resistance through the inhibition of LDHA in oral squamous cell carcinoma. Oncol Lett. 2015;9:1827-32.

6. Hartner L. Chemotherapy for Oral Cancer. Dent Clin North Am. 2018;62:87-97.

7. Wall ME, Wani MC, Cooke CE, Palmer KH, McPhail AT, Sim GA. Plant antitumor agents I. The isolation and structure of camptothecin, a novel alkaloidal leukemia and tumor inhibitor from Camptotheca acuminata. J Am Chem Soc. 1966;88:3888-90.

8. Staker BL, Hjerrild K, Feese MD, Behnke CA, Burgin AB Jr, Stewart L. The mechanism of topoisomerase I poisoning by a camptothecin analog. Proc Natl Acad Sci USA. 2002;99:15387-92.

9. Staker BL, Feese MD, Cushman M, Pommier Y, Zembower D, Stewart L, et al. Structures of three classes of anticancer agents bound to the human topoisomerase IDNA covalent complex. J Med Chem. 2005;48:2336-45.

10. Pommier Y. Topoisomerase I inhibitors: camptothecins and beyond. Nature Rev. 2006;6:789-802.

11.Palnchon SM, Wuerzberger S, Frydman B, Witiak DT, Huston P, Church DR, et al. â-lapachone mediated apoptosis in human promyelocytic leukemia (HL-60) and human prostate cancer cells: a p53 independent respo nse. Cancer Res. 1995;55:3706-11.

12. Ohyama T, Li Y, Utsugi T, Irie S, Yamada Y, Sato T. A dual topoisomerase inhibitor, TAS-103, induces apoptosis in human cancer cells. Jpn J Cancer Res. 1999;90:691-8.

13. Tolis C, Peters GJ, Ferreira CG, Pinedo HM, Giaccone G. Cell cycle distu rbances and apoptosis induced by topotecan and gemcitabine on human lung cancer cell lines. Eur J Cancer. 1999;35:796-807.

14. World Cancer Report 2014. World Health Organization. 2014. Chapter 5.8 .

15.Wu TT, Zhou SH. Nanoparticle-Based Targeted Therapeutics in Head-And-Neck Cancer. Int J Med Sci. 2015;12:187-200.

16. Vairaktaris E, Spyridonidou S, Papakosta V, Vylliotis A, Lazaris A, Perrea D, et al. The hamster model of sequential oral oncogenesis. Oral Oncol. 2008;44:315-24.

17. Taraboletti G, Giavazzi R. Modelling approaches for angiogenesis. Eur J Cancer. 2004;40:881-9.

18. Faccin Bampi V, Ferreira Vilela W, Vilela Gonçalves R, Tavares Rheingantz MG, Minello LF, Braga da Silva JL, et al. The promoting effect of carbamide peroxide teeth bleaching gel in a preclinical model of head and neck cancer in hamster buccal pouch. Clin Exp Otorhinolaryngol. 2014;7:210-5.

19. Sanli UA, Karabulut B, Uslu R, Korkut M, Goker E. Single-agent irinotecan for recurrent/metastatic colorectal cancer: a retrospective analysis. Med Princ Pract. 2006;15:288-92.
20. Rosati G1, Cordio S. Single-agent irinotecan as secondline weekly chemotherapy in elderly patients with advanced colorectal cancer. Tumori. 2000;92(4):290-4.

21. Rapic S, Vangestel C, Elvas F, Verhaeghe J, den Wyngaert TV, Wyffels L, et al. Evaluation of [18F]CPT18 as a Substrate-Based Apoptosis Imaging Agent for the Assessment of Early Treatment Response in Oncology. Mol Imaging Biol. 2017;19:560-9.

22. Qiao L, Pizzolo G, Melamed MR. Effects of selected chemotherapeutic agents on PCNA expression in prostate carcinoma cell lines. Urol Res. 1994;22:171-6.

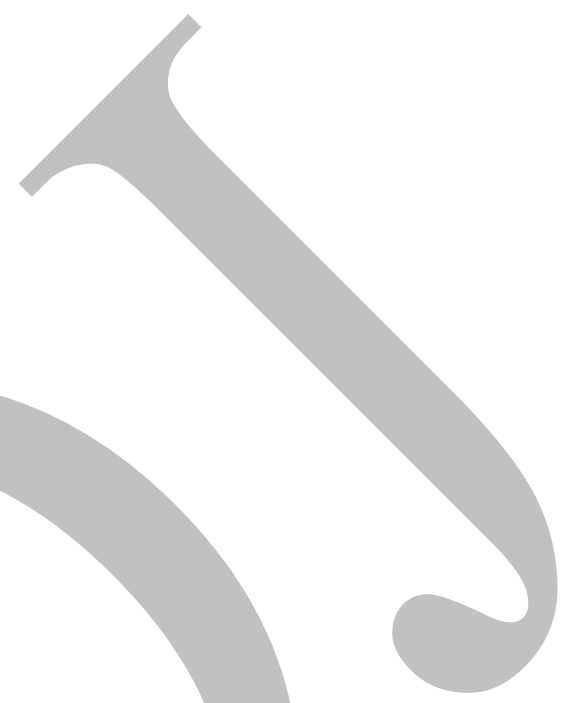

